\title{
Trends in Precipitation Characteristics in Bangladesh from 1950 to 2008
}

\author{
Nobuhiko Endo ${ }^{1}$, Jun Matsumoto ${ }^{1,2}$, Taiichi Hayashi ${ }^{3}$, Toru Terao ${ }^{4}$, Fumie Murata ${ }^{5}$, \\ Masashi Kiguchi ${ }^{6}$, Yusuke Yamane ${ }^{7}$, and Md. Shah Alam ${ }^{8}$ \\ ${ }^{1}$ Japan Agency for Marine-Earth Science and Technology, Kanagawa, Japan \\ ${ }^{2}$ Department of Geography, Tokyo Metropolitan University, Tokyo, Japan \\ ${ }^{3}$ Disaster Prevention Research Institute, Kyoto University, Kyoto, Japan \\ ${ }^{4}$ Faculty of Education, Kagawa University, Takamatsu, Japan \\ ${ }^{5}$ Faculty of Science, Kochi University, Kochi, Japan \\ ${ }^{6}$ Institute of Industrial Science, The University of Tokyo, Tokyo, Japan \\ ${ }^{7}$ Faculty of Education, Tokoha University, Shizuoka, Japan \\ ${ }^{8}$ Bangladesh Meteorological Department, Dhaka, Bangladesh
}

\begin{abstract}
We analyzed trends in precipitation characteristics at 12 weather stations in Bangladesh using data from 1950 to 2008 and a non-parametric Mann-Kendall's tau test. It was found that the annual precipitation amount and the number of wet days tended to increase at almost all the stations. The number of days with weak precipitation $(<3 \mathrm{~mm})$ showed increasing tendency; the number of days with daily precipitation exceeding $10 \mathrm{~mm}$ increased at three stations; and the number of days with daily precipitation exceeding $20 \mathrm{~mm}$ increased at two stations. Heavy rainfall index showed no clear trend, and was dominated by inter-annual and/or decadal variations. During the pre-monsoon season, seasonal precipitation amount and the number of wet days increased, and the number of days with weak precipitation $(<3 \mathrm{~mm})$ also increased. Changes in the monsoon and post-monsoon seasons were insignificant.
\end{abstract}

(Citation: Endo, N., co-authors, 2015: Trends in precipitation characteristics in Bangladesh from 1950 to 2008. SOLA, 11, 113-117, doi:10.2151/sola.2015-027.)

\section{Introduction}

Bangladesh is a lowland country located in the Indian monsoon region. During the summer monsoon season (JuneSeptember), much of the precipitation was brought by the monsoon low (pressure system) originated from the Bay of Bengal and moved along the Ganges. Precipitation in Bangladesh shows clear intraseasonal variation with time scales of 7-25 days during the monsoon season (Fujinami et al. 2011; Hatsuzuka et al. 2014). Precipitation caused by severe local convective storms is predominant in the pre-monsoon (March-May) season (Rafiuddin et al. 2010; Yamane et al. 2010). Cyclones also occasionally affect Bangladesh in the pre-monsoon season and the post-monsoon season (October-November). Since agriculture is a major economic component in Bangladesh, meteorological drought and heavy precipitation have large impacts on the society and agricultural activity there. In addition, most of Bangladesh is at risk for flooding due to heavy rainfall in Bangladesh and its surrounding regions.

Changes in precipitation characteristics have been investigated for many parts of the world (e.g., Karl and Knight 1998; Frich et al. 2002; Klein Tank and Können 2003). For Asian countries, trends in precipitation characteristics were investigated for India (Sen Roy and Balling 2004; Goswami et al. 2006; Goswami et al. 2010; Dash et al. 2009), China (e.g., Zhai et al. 2004; Endo et al. 2005), and some other Southeast Asian countries (Choi et al. 2009; Endo et al. 2009). Goswami et al. (2006) found that the fre-

Corresponding author: Nobuhiko Endo, Research and Development Center for Global Change, Japan Agency for Marine-Earth Science and Technology, 2-15 Natsushima-cho, Yokosuka, Kanagawa, 237-0061, Japan. E-mail: nobu@jamstec.go.jp. (C2015, the Meteorological Society of Japan. quency and intensity of extreme rainfall increased in central India for the period 1951-2004. Dash et al. (2009) demonstrated that heavy precipitation days increased in central northeast and northeast India during the monsoon season for the period 1951-2004, and moderate rain days decreased in these regions. In contrast to Dash et al. (2009), Goswami et al. (2010) reported that extreme rain event frequency tended to decrease at 15 stations in northeast India from 1975 to 2006.

Shahid (2010) analyzed trends in annual and seasonal precipitation for the period 1958-2007 in Bangladesh, and showed that the annual and pre-monsoon precipitation increased at the rates of 5.53 and $2.47 \mathrm{~mm}$ year $^{-1}$, respectively. Shahid (2011) examined trend in extreme rainfall in Bangladesh, and showed increasing trend in terms of some heavy precipitation indices. From agricultural point of view, it is important not only to examine changes in heavy precipitation but also to describe variation in weak precipitation $(<3 \mathrm{~mm})$. Weak precipitation is one of important water resources in Bangladesh during non-monsoon seasons. Shahid (2011) analyzed 10 annual precipitation indices, including four indices for the pre-monsoon season, and one index for the monsoon season. Therefore, an assessment of trends in various precipitation types, including weak precipitation, for each season is useful. The object of this study is to describe long-term trends in precipitation characteristics using the daily precipitation data in Bangladesh for the period 1950-2008.

\section{Data and method}

We used the daily precipitation data at 17 stations, which have longer records, provided by the Bangladesh Meteorological Department. We checked missing records in the daily precipitation data first. Missing records frequently appeared in the 1960's and around the period of the independence war of Bangladesh in 1971. To evaluate long-term trends in precipitation characteristics, we allowed data gaps of less than $10 \%$ of the year. If there are more than $10 \%$ of missing values in the monsoon season (JuneSeptember), we also discarded the year. The daily precipitation data were subjected to visual inspection for extremely large daily precipitation amount and anomalously long dry period from March to November. Homogeneity of the daily precipitation data was checked using the four statistical tests recommended by Wijngaard et al. (2003): the standard normal homogeneity test, the Buishand range test, the Pettit test, and the Von Neumann ratio test. Finally, 12 stations with the daily precipitation data were passed the four statistical tests at the 1\% significant level, and considered to be homogeneous are selected for evaluating the trends. These stations are shown in Fig. 1 and listed in Table S1.

Eleven precipitation-related indices were calculated (Table 1). To describe changes of the entire precipitation distribution, we calculated total amount of precipitation (PRCPTOT), simple daily intensity index (SDII) and the number of wet days (WDAY), which refers to a day with at least $1 \mathrm{~mm}$ of precipitation. To 


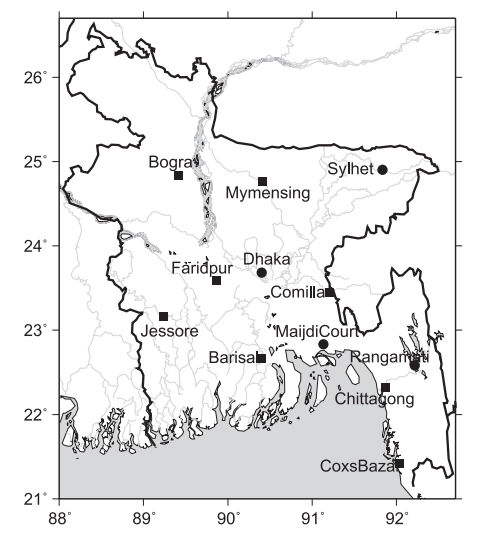

Fig. 1. Distribution of stations used in this study. Circle indicates data available from 1950, and square means data available starting in a year from 1951 to 1957.

describe changes in frequency of heavy rainfall, we employed threshold-based index defined by three threshold levels $(10,20$, and $50 \mathrm{~mm}$ ). Percentiles based on the indices of R95p and R99p were also calculated. Climatological wet day percentiles were calculated for the period 1979-2008. Annual longest consecutive wet days (CWD) and consecutive dry days (CDD) were employed for explaining changes in duration. In addition, a new index of $\mathrm{R} 03 \mathrm{~mm}$ was introduced for illustrating changes in weak rainfall. $\mathrm{R} 03 \mathrm{~mm}$ is the number of days with precipitation exceeding or equal to $1 \mathrm{~mm}$ and less than or equal to $3 \mathrm{~mm}$. In the recent 30 years, R03mm accounted for $8-9 \%$ of all the wet days at the 12 stations. All indices were calculated annually from January to December. The indices of PRCPTOT, WDAY, R03mm, R10mm, $\mathrm{R} 20 \mathrm{~mm}$, and R50mm were also calculated for the pre-monsoon (March-May), the monsoon (June-September) and the post-monsoon (October-November) seasons, respectively. We did not calculate the indices for the winter season (December-February) because WDAY was very small.

Since almost all the indices calculated do not follow the normal distribution, the non-parametric Mann-Kendall's tau test (MK test) was used to evaluate the trend in the time series of climatological and hydrological data (e.g., Hirsch et al. 1982; Lettenmaier et al. 1994). The MK test was applied to the precipitation index time series for evaluating statistical significance of each trend in this study. We consider a trend is statistically significant if it is significant at the 5\% level. The magnitude of the trend was obtained by a non-parametric Kendall's tau based slope estimator (Sen 1968; Wang and Swail 2001). Each trend was evaluated from the first year when the data was available to year 2008. Since data availability is different among the stations as shown in Table S1, we also calculated the trends for a common period of data availability, namely, from 1957 to 2008 . The trends obtained
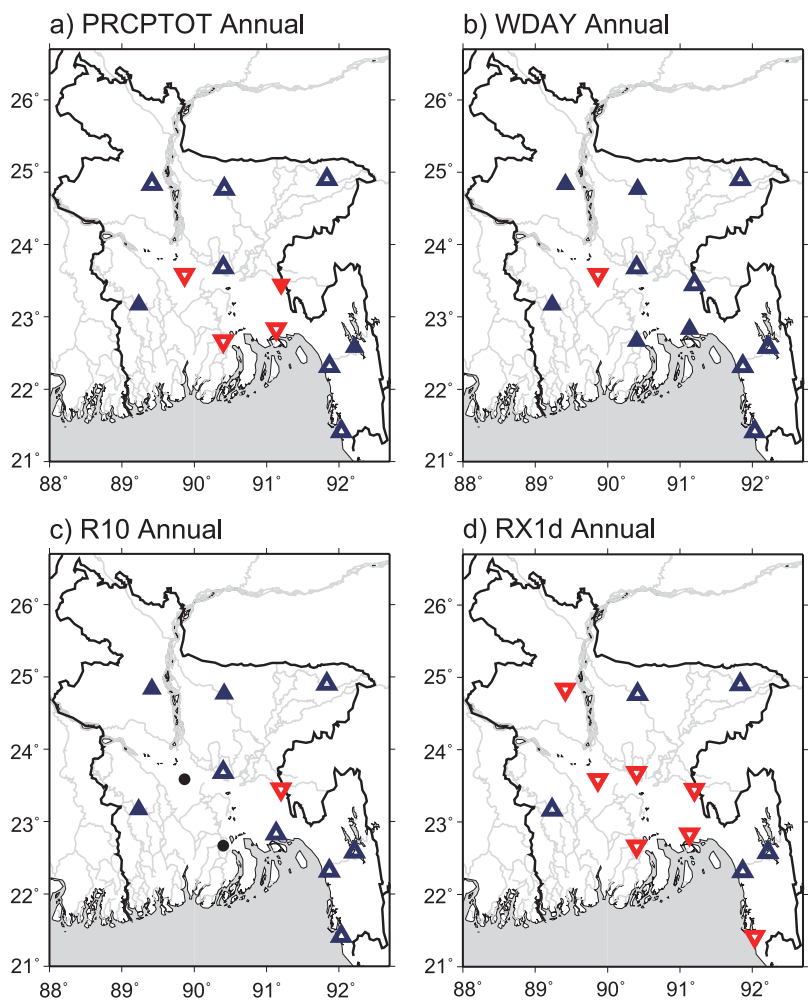

d) RX1d Annual

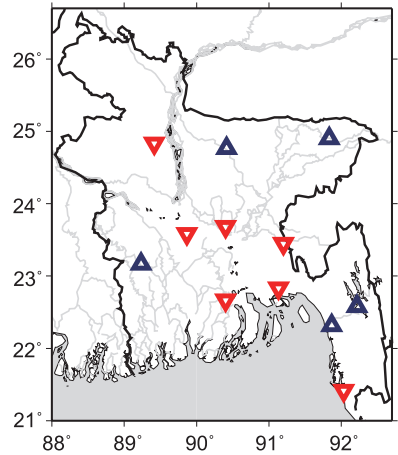

Fig. 2. Trends for annual index time series for a) annual precipitation amount (PRCPTOT), b) the number of wet days (WDAY), c) the number of heavy precipitation days (R10mm), and d) annual maximum 1-day precipitation amount. Upward blue (downward red) triangle corresponds to increasing (decreasing) trend. Filled triangle shows the trend is significant at the $5 \%$ level, and filled circle means no trend.

for the original period and the common period are very similar. Therefore, we will only present the trends for the period from the first year when the data was available to year 2008 .

To examine relationship between the precipitation indices and the basin wide sea surface temperature variation in the decadal or longer time scale, the unfiltered Atlantic Multidecadal Oscillation (AMO; Kushnir 1994) index and the unfiltered Interdecadal Pacific Oscillation (IPO; Zhang et al. 1997) are obtained from NOAA/ESRL.

\section{Results}

Figure 2a shows the spatial distribution of trends in total annual precipitation amount (PRCPTOT), with increasing

Table 1. Precipitation indices and their definitions. $R R$ is the daily precipitation rate. A wet day has $R R \geq 1 \mathrm{~mm}$, while a dry day has $R R<1 \mathrm{~mm}$.

\begin{tabular}{|c|c|c|}
\hline Index & Definitions & Units \\
\hline PRCPTOT & Annual total precipitation from wet days & $\mathrm{mm}$ \\
\hline WDAY & Number of days with daily precipitation $\geq 1 \mathrm{~mm}$ & days \\
\hline SDII & Average precipitation from wet days & $m m$ day $^{-1}$ \\
\hline $\mathrm{R} 10 \mathrm{~mm}$ & Heavy precipitation days (Number of days per year with precipitation amount $\geq 10 \mathrm{~mm}$ ) & days \\
\hline $\mathrm{R} 20 \mathrm{~mm}$ & Very heavy precipitation days (Number of days per year with precipitation amount $\geq 20 \mathrm{~mm}$ ) & days \\
\hline $\mathrm{R} 50 \mathrm{~mm}$ & Number of days per year with precipitation amount $\geq 50 \mathrm{~mm}$ & days \\
\hline R95p, R99p & $\begin{array}{l}\text { Precipitation amount per year above a site-specific threshold value for very and extremely wet days, calculated as the } \\
\text { 95th and 99th percentile of the distribution of daily precipitation amounts on days with } 1 \mathrm{~mm} \text { or more precipitation in } \\
\text { the 1979-2008 baseline period. }\end{array}$ & $\mathrm{mm}$ \\
\hline RX1day & Annual maximum 1-day precipitation & $\mathrm{mm}$ \\
\hline RX5day & Annual maximum consecutive 5-day precipitation & $\mathrm{mm}$ \\
\hline CWD & Annual maximum number of consecutive wet days & days \\
\hline CDD & Annual maximum number of consecutive dry days & days \\
\hline $\mathrm{R} 03 \mathrm{~mm}$ & Number of days per year or season with precipitation amount $1 \mathrm{~mm} \leq \mathrm{RR} \leq 3 \mathrm{~mm}$. & days \\
\hline
\end{tabular}


(decreasing) trends at eight (four) stations. However, statistically significant increasing (decreasing) trends in PRCPTOT were only observed at two stations (one station) (Fig. 2a). The decreasing tendency was observed at the stations near the mouth of the Ganges, while the increasing trends existed at the northern and southeastern stations. These results are consistent with the results of Shahid (2010).

WDAY increased at 11 stations, with statistically significant trends observed at five stations (Figs. $2 b$ and 3). SDII at six stations showed declining tendency, but only two of these stations had statistically significant decreasing trends. SDII had increasing tendency at the remaining four stations. In Bangladesh, PRCPTOT and WDAY appeared to be increasing country-wide, while the changes in SDII were small.

For the threshold-based indices, R03mm, R10mm and R20mm had increasing tendency among the stations (Fig. 3). Increasing trends with statistical significance were observed at four, three and two stations for R03mm, R10mm and R20mm, respectively. The spatial distribution of trend in R10mm is shown in Fig. 2c. Increasing trends distributed all over the country, and statistically significant increases were only in western and northwestern Bangladesh. R50mm, on the other hand, increased at six stations without statistical significance (Fig. 3). These trends in the threshold-based indices suggest that the frequency of weak precipitation increased, while the frequency of heavy precipitation remained the same.

Figure 4 shows the time series of R03mm, which is the arithmetic average of $\mathrm{R} 03 \mathrm{~mm}$ at 12 stations. It clearly indicates that decadal variation dominated in $\mathrm{R} 03 \mathrm{~mm}$. We also found that inter-annual and/or decadal variability in R50mm was obvious in Bangladesh (figure not shown). Recently, Joshi and Rai (2015) found that the monsoon rainfall and moderate/heavy rainfall tends

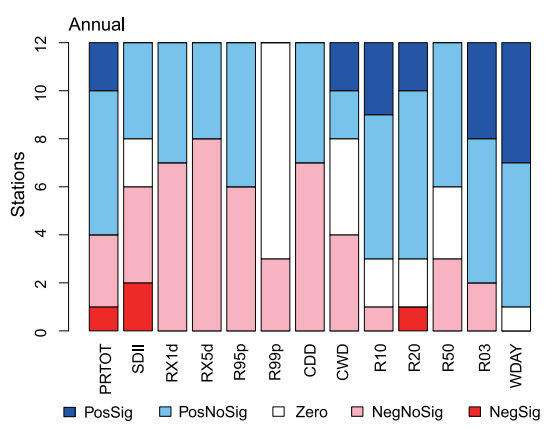

Fig. 3. Summary of trends in annual indices. Blue (red) shows positive (negative) trends significant at the 5\% level. Light blue (pink) means positive (negative) trend without statistical significance, and white indicates zero trend. Ordinate is the number of stations.

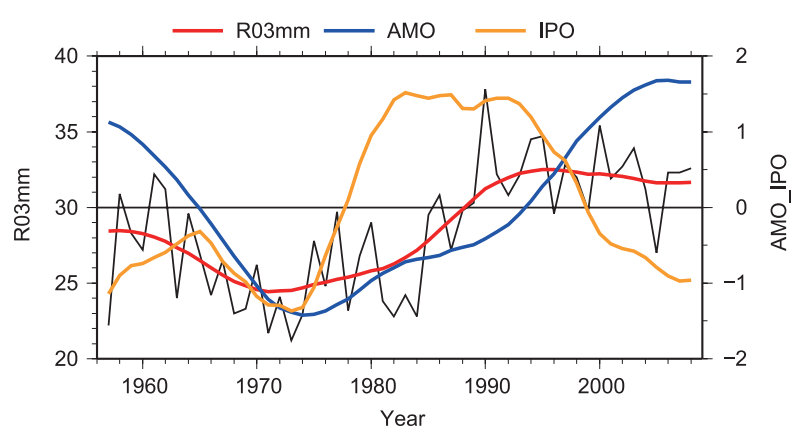

Fig. 4. Time series of the annual number of weak rainfall day (R03mm; thin black line), the filtered R03mm (red line), the filtered annual AMO index (blue line), and the filtered IPO index (orange line). Annual average of the unfiltered AMO and IPO index were prepared. Then a 9-year moving average was applied twice to the time series following Dong and Dai (2015). Statistically significance of the correlation coefficient are evaluated by a two-tailed Student $t$ test with autocorrelation being accounted for. to decrease in the northeast India during positive AMO and negative IPO. The filtered annual $\mathrm{R} 03 \mathrm{~mm}$ and the filtered annual AMO/IPO indices are also shown in Fig. 4. AMO shows positive correlation $(\mathrm{r}=0.749)$ without statistical significance, and IPO has low correlation coefficient $(r=0.308)$. Thus, $R 03 \mathrm{~mm}$ tends to be smaller during the negative AMO. It is worthwhile analyzing the multidecadal variation in the precipitation characteristics in Bangladesh and the impact of AMO/IPO on the precipitation characteristics. However, it should be another study to scrutinize the multidecadal variation in the precipitation characteristics.

Figure $2 \mathrm{~d}$ shows the spatial distribution of RX1d. Increasing (decreasing) trends without statistical significance were observed at five (seven) stations. In addition, RX5d also had no statistically significant trends at these stations. In fact, inter-annual variation was large in both RX1d and RX5d.

The 95th percentile and the 99th percentile of WDAY are defined by ranking the wet days over the baseline period 19792008. The range of the 95th percentile is from 54 to $105 \mathrm{~mm}$ for these stations. The 95th percentile tended to be large at the southeastern stations. For the 99th percentile, the range is 105 to $183 \mathrm{~mm}$. Increasing trends and decreasing trends in R95p can be observed at six stations each without statistical significance (Fig. 3). No trend in R99p was observed at nine stations (Fig. 3). The time series of R95p (R99p) show that there were years without contributions from heavy (very heavy) precipitation (figure not shown). This means that R95p (R99p) was emergent sporadically, and inter-annual variation dominated in the time series of R95p (R99p). In contrast to these results in Bangladesh, the frequency above 99th percentile threshold of daily precipitation and the intensity above 99th percentile of precipitation events increased in West Bengal for the period 1951-2003 (Krishnamurthy et al. 2009).

Annual longest consecutive wet days (CWD) had statistically significant increasing trends at two stations (Fig. 3). However, there was no country-wide coherent tendency for CWD. In Bangladesh, dry condition prevails during winter and there is a possibility of meteorological drought, which has a large impact on agriculture and economy. Trends in annual longest consecutive dry days (CDD) were split into increasing or decreasing tendencies at these stations (Fig. 3). Therefore, changes in meteorological drought were uncertain by analyzing the annual CDD index series.

Figure 5 shows the summary of trends in the precipitation indices for the pre-monsoon, monsoon and post-monsoon seasons. Seasonal total precipitation and WDAY in the pre-monsoon season showed increasing tendency over much of the country. Statistically significant increasing trend in WDAY was observed in southeastern and northern Bangladesh (Fig. 6a). Increase of the pre-monsoon total precipitation in Bangladesh was reported by Shahid (2011). An increasing trend of the pre-monsoon precipitation in West Bengal was reported by Sadhukhan et al. (2000). On the contrary, the pre-monsoon precipitation decreased in the Brahamaputra and Barak basins in northeastern India (Deka et al. 2013). Therefore, the pre-monsoon precipitation had different tendencies in Bangladesh and its surrounding regions .

R50mm had increasing tendency at only three stations, while the other threshold-based indices for the pre-monsoon season

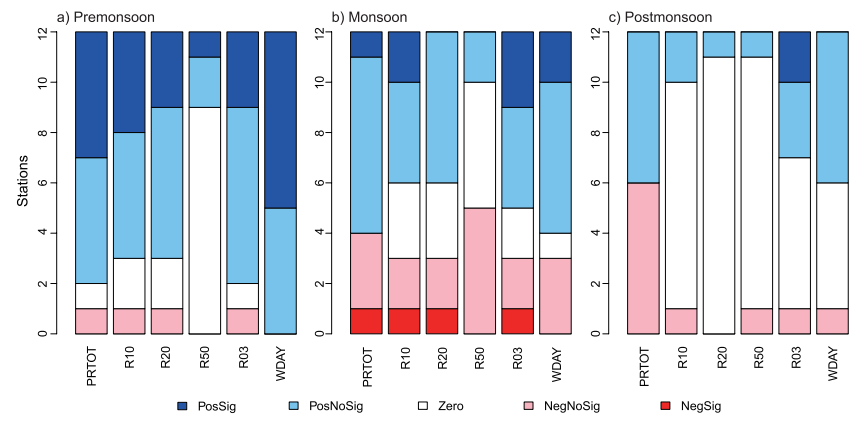

Fig. 5. Same as Fig. 3, except for trends in seasonal indices. 


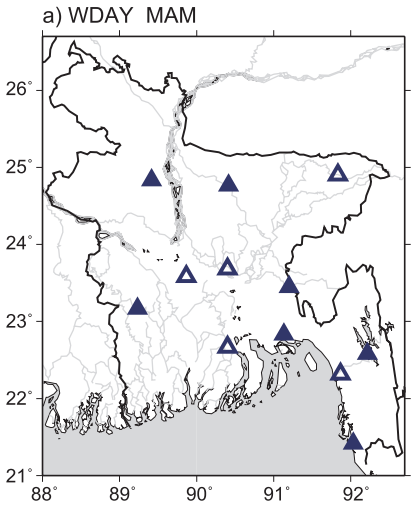

b) R03mm MAM

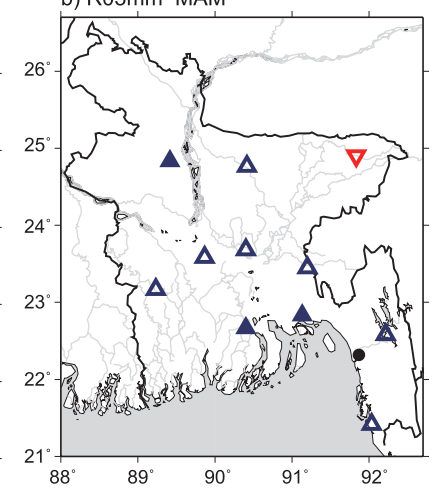

Fig. 6. Trends in seasonal index time series for a) the number of wet day (WDAY) and $b$ ) the number of day with $1 \leq \mathrm{RR} \leq 3 \mathrm{~mm}$ (R03mm) for the pre-monsoon season (March-May). Upward blue (downward red) triangle corresponds to increasing (decreasing) trend. Filled triangle shows the trend is significant at the $5 \%$ level, and filled circle means no trend.

(R03mm, R10mm and R20mm) indicate increasing tendency at more than nine stations. Figure $6 \mathrm{~b}$ is the spatial distribution of trend in R03mm for the pre-monsoon season. Increasing tendency existed at 10 stations, and decreasing tendency appeared only in Sylhet in the northeast Bangladesh, where climatologically largest precipitation amount in the pre-monsoon season was observed. In the western part of Bangladesh, increasing tendencies of $\mathrm{R} 03 \mathrm{~mm}$ and WDAY suggest that the possibility of meteorological drought appeared to become smaller for the pre-monsoon season in the recent decades.

For the monsoon season, five out of six indices show increasing tendency at more than six stations (Fig. 5b). Increasing trend in total precipitation in the monsoon season was observed at eight stations. These increasing trends are consistent with the results of Kripalani et al. (1996) and Shahid (2010). R03mm shows increasing tendency at seven stations, but statistically significant increasing trend was observed only at three stations. Still, the frequency of weak precipitation days appeared to be increasing in Bangladesh during the monsoon season. Increasing trends with statistical significance in WDAY and R10mm were only observed at two stations. On the other hand, R50mm had no statistically significant trend. For the post-monsoon season, statistically significant trend for R03mm was only observed at two stations (Fig. 5c). Other indices showed no statistically significant trends.

We found that the frequency of weak precipitation days had increasing trends in the pre-monsoon and monsoon seasons, while the heavy precipitation frequency showed no trend in Bangladesh. Trend in light precipitation was previously reported for limited countries. Karl et al. (1995) reported that the proportion derived from lighter precipitation (trace to $2.5 \mathrm{~mm}_{\text {day }}{ }^{-1}$ ) increased in the U.S.A. On the other hand, decreasing trends in lighter precipitation classes were observed in Japan (Fujibe et al. 2005) and China (Liu et al. 2005; Liu et al. 2010). Since Bangladesh is located in the tropical monsoon region, large-scale environment and precipitation-producing system in and around Bangladesh are very different from the other countries mentioned above. Increase of the weak precipitation frequency could be attributed to large-scale environment and precipitation-producing system in and around Bangladesh.

Precipitation in the pre-monsoon season in Bangladesh is brought by isolated convections (Islam et al. 2004; Terao 2008), convective clouds developed around mountain ranges associated with moist air flow from the Bay of Bengal (hereafter BB; Terao 2008), and organized convective storms (Islam et al. 2005; Raffiudin et al. 2010; Dalal et al. 2012). Jadhav and Munot (2009) reported that the sea surface temperature (SST) in BB warmed up in the pre-monsoon and monsoon seasons. Warmer SST suggests that precipitable water over BB increased accordingly. Actually, precipitable water estimated from microwave imager increased in BB for the period 1988-2008 (figure not shown). The air from $\mathrm{BB}$ with more moisture could be uplifted in the hilly regions to form orographic clouds and/or convective storms. These clouds may increase the frequency of weak precipitation in northern and southeastern parts of Bangladesh. In addition, isolated convective clouds related to sea breeze circulations near the coast of BB may also produce weak precipitation (Lohar et al. 1994).

APHRODITE gridded precipitation dataset (Yatagai et al. 2012) has been used by several papers (e.g., Hatsuzuka et al. 2014). Precipitation indices obtained from BMD data and that from APHRODITE were different in climatologically (Fig. S1). R03mm (R50mm) is tended to be larger (smaller) in APHRODITE. Although APHRODITE is important dataset for monsoon Asian countries, some cautions are needed for evaluation of extreme precipitation using APHRODITE.

\section{Conclusion}

Changes of precipitation characteristics in Bangladesh were investigated using daily precipitation data provided by the Bangladesh Meteorological Department for the period 1950-2008. Quality check and homogeneity check procedures were applied to the daily data. Twelve stations were selected for analysis. Thirteen indices were calculated to represent precipitation characteristics, including precipitation amount, frequency and intensity. The annual precipitation amount and the number of wet days tended to increase at almost all the stations. The number of days with weak precipitation showed increasing tendency over Bangladesh. The number of days with daily precipitation exceeding $10 \mathrm{~mm}$ increased at three stations, and the number of days with daily precipitation exceeding $20 \mathrm{~mm}$ increased at two of the three stations. During the pre-monsoon season, seasonal total precipitation and the number of wet days increased, and the number of days with weak precipitation increased. Heavy rainfall indices showed that inter-annual and/or decadal variations dominated. Precipitation producing system related to heavy precipitation may also vary in inter-annual and/or decadal time scales. A detailed analysis is needed to reveal the inter-annual and/or decadal variations in large-scale circulation and disturbances associated with heavy rainfall events.

\section{Acknowledgements}

This study was partially supported by the JSPS KAKENHI (grant numbers 11691151, 12740269, 12574020, 15651103, 17255002, 18256005, 21403005, 23241057, 23240122, and 26220202), the MEXT 21st Century COE Program of Kyoto University, "Elucidation of the Active Geosphere from Asia and Oceania to the World," the Environment Research and Technology Development Fund (S-10) of the Ministry of the Environment, Japan, and the Japan-Bangladesh joint study project on floods by the Japanese International Cooperation Agency (JICA). It was also supported by the Japan EOS Promotion Program (JEPP) of the MEXT, "Development of rainfall observation system in Southeast Asia."

Edited by: H.-H. Hsu

\section{Supplement}

Table S1 is the list of the stations used in this study.

Tables S2 and S3 are the trends per decade for the indices of precipitation for annual time series and seasonal time series, respectively.

Figure S1 is climatology of R03mm and R50mm obtained from BMD rain gauge data and APHRODITE rainfall data. 


\section{References}

Dong, B., and A. Dai, 2015: The influence of the Interdecadal Pacific Oscillation on temperature and precipitation over the Globe. Clim. Dyn., doi:10.1007/s00382-015-2500-x.

Caesar, J., and co-authors, 2011: Changes in temperature and precipitation extremes over the Indo-Pacific region from 1971 to 2005. Int. J. Climatol., 31, 791-801, doi:10.1002/joc.2118.

Choi, G., and co-authors, 2009: Changes in means and extreme events of temperature and precipitation in the Asia-Pacific Network region, 1955-2007. Int. J. Climatol., 29, 1906-1925, doi: 10.1002/joc. 1979.

Dalal, S., D. Lohar, S. Sarkar, I. Sadhukhan, and G. C. Debnath, 2012: Organizational modes of squall-type mesoscale convective systems during premonsoon season over eastern India. Atmos. Res., 106, 120-138, doi:10.1016/j.atmosres.2011.12.002.

Dash, S. K., M. A. Kulkarni, U. C. Mohanty, and K. Prasad, 2009: Changes in the characteristics of rain events in India. J. Geophys. Res., 114, doi:10.1029/2008JD010572.

Deka, R. L., C. Mahanta, H. Pathak, K. K. Nath, and S. Das, 2013: Trends and fluctuations of rainfall regime in the Brahmaputra and Barak basins of Assam, India. Theor. Appl. Climatol., 114, 61-71, doi:10.1007/s00704-012-0820-x.

Endo, N., B. Ailikun, and T. Yasunari, 2005: Trends in precipitation amounts and the number of rainy days and heavy rainfall events during summer in China from 1961 to 2000. J. Meteor. Soc. Japan, 83, 621-631, doi:10.2151/jmsj.83.621.

Endo, N., J. Matsumoto, and T. Lwin, 2009: Trends in precipitation extremes over Southeast Asia. SOLA, 5, 168-171, doi:10.2151/ sola.2009-043.

Frich, P., L. V Alexander, B. Gleason, M. Haylock, A. M. G. K. Tank, and T. Peterson, 2002: Observed coherent changes in climatic extremes during the second half of the twentieth century. Clim. Res., 19, 193-212.

Fujibe, F., N. Yamazaki, M. Katsuyama, and K. Kobayashi, 2005: The increasing trend of intense precipitation in Japan based on fourhourly data for a hundred years. SOLA, 1, 41-44, doi:10.2151/ sola.2005-012.

Fujinami, H., D. Hatsuzuka, T. Yasunari, T. Hayashi, T. Terao, F. Murata, M. Kiguchi, Y. Yamane, J. Matsumoto, Md. Nazrul Islam, and A. Habib, 2011: Characteristics intraseasonal oscillation of rainfall and its effect on interannual variability over Bangladesh during boreal summer. Int. J. Climatol., 31, 1192-1204, doi:10.1002/joc. 2146 .

Goswami, B. B., P. Mukhopadhyay, R. Mahanta, and B. N. Goswami, 2006: Multiscale interaction with topography and extreme rainfall events in the northeast Indian region. J. Geophys. Res., 115, D12114, doi:10.1029/2009/JD012275.

Goswami, B. N., V. Venugopal, D. Sengupta, M. S. Madhusoodanan, and P. K. Xavier, 2010: Increasing trend of extreme rain events over India in a warming environment. Science, 314, 1442-1445, doi:10.1126/science.1132027.

Hatsuzuka, D., T. Yasunari, and H. Fujinami, 2014: Characteristics of low pressure systems associated with intraseasonal oscillation of rainfall over Bangladesh during boreal summer. Mon. Wea. Rev., 142, 4758-4774, doi:10.1175/MWR-D-13-00307.1.

Hirsch, R. M., J. R. Slack, and R. A. Smith, 1982: Techniques of trend analysis for monthly water quality data. Water Resour. Res., 18, 107-121, doi:10.1029/WR018i001p00107.

Islam, M. N., T. Hayashi, H. Uyeda, T. Terao, and K. Kikuchi, 2004: Diurnal variations of cloud activity in Bangladesh and north of the Bay of Bengal in 2000. Rem. Sens. Environ., 90, 378-388.

Islam, M. N., T. Hayashi, T. Terao, H. Uyeda, and K. Kikuchi, 2005: Characteristics of precipitation systems analyzed from radar data over Bangladesh. J. Nat. Disaster Sci., 27, 17-23.

Jadhav, S. K., and A. A. Munot, 2009: Warming SST of Bay of Bengal and decrease in formation of cyclonic disturbances over the Indian region during southwest monsoon season. Theor. Appl. Climatol., 96, 327-336, doi:10.1007/s00704-008-0043-3.

Joshi, M. K., and A. Rai, 2015: Combined interplay of the Atlantic multidecadal oscillation and the interdecadal Pacific oscillation on rainfall and its extremes over Indian subcontinent. Clim. Dyn., doi:10.1007/s00382-014-2333-z.

Karl, T. R., and R. W. Knight, 1998: Secular trends of precipitation amount, frequency, and intensity in the United States. Bull.
Amer. Meteor. Soc., 79, 231-241.

Karl, T. R., R. W. Knight, and N. Plummer, 1995: Trends in highfrequency climate variability in the twentieth century. Nature, 377, 217-220.

Klein Tank, A. M. G., and co-authors, 2006: Changes in daily temperature and precipitation extremes in central and south Asia. $J$. Geophys. Res., 111, D16105, doi:10.1029/2005JD006316.

Kripalani, R. H., S. Inamdar, and N. a. Sontakke, 1996: Rainfall variability over Bangladesh and Nepal: Comparison and connections with features over India. Int. J. Climatol., 16, 689-703.

Krishnamurthy, C. K. B., U. Lall, and H. Kwon, 2009: Changing frequency and intensity of rainfall extremes over India from 1951 to 2003. J. Climate, 22, 4737-4746, doi:10.1175/2009JCLI 2896.1 .

Kushnir, Y., 1994: Interdecadal variations in North Atlantic sea surface temperature and associated atmospheric conditions. $J$. Climate, 7, 141-157.

Lettenmaier, D. P., E. F. Wood, and J. R. Wallis, 1994: Hydroclimatological trends in the Continental United States, 1948-88. J. Climate, 7, 586-607.

Liu, B., M. Xu, M. Henderson, and Y. Qi, 2005: Observed trends of precipitation amount, frequency, and intensity in China, 1960-2000. J. Geophys. Res., 110, D08103, doi:10.1029/2004 JD004864.

Liu, B., M. Xu, and M. Henderson, 2010: Where have all the showers gone? Regional declines in light precipitation events in China, 1960-2000. Int. J. Climatol., 31, 1177-1191, doi:10.1002/joc. 2144.

Lohar, D., B. Pal, and B. Chakravarty, 1994: Sea breeze activity at an inland station Kharagpur (India) - A case study. Bound.-Layer Meteor., 67, 427-434.

Rafiuddin, M., H. Uyeda, and M. N. Islam, 2010: Characteristics of monsoon precipitation systems in and around Bangladesh. Int. J. Climatol., 1055, doi:10.1002/joc. 1949.

Sadhukhan, I., D. Lohar, and D. K. Pal, 2000: Premonsoon season rainfall variability over Gangetic west Bengal and its neighbourhood, India. Int. J. Climatol., 20, 1485-1493.

Sen, P. K., 1968: Estimates of the regression coefficient based on Kendall's tau. J. Amer. Stat. Assoc., 63, 1379-1389.

Sen Roy, S., and R. C. Balling, 2004: Trends in extreme daily precipitation indices in India. Int. J. Climatol., 24, 457-466, doi: $10.1002 /$ joc. 995 .

Shahid, S., 2010: Recent trends in the climate of Bangladesh. Clim. Res., 42, 185-193, doi: $10.3354 / \mathrm{cr} 00889$.

Shahid, S., 2011: Trends in extreme rainfall events of Bangladesh. Theor. Appl. Climatol., 104, 489-499, doi:10.1007/s00704-0100363-y.

Terao, T., M. N. Islam, F. Murata, and T. Hayashi, 2008: High temporal and spatial resolution observations of meso-scale features of pre- and mature summer monsoon cloud systems over Bangladesh. Nat. Hazards, 44, 341-351, doi:10.1007/s11069-0079128-z.

Wang, X. L., and V. R. Swail, 2002: Trends of Atlantic wave extremes as simulated in a 40-yr wave hindcast using kinematically reanalyzed wind fields. J. Climate, 15, 1020-1035.

Wijngaard, J. B., a. M. G. Klein Tank, and G. P. Können, 2003: Homogeneity of 20th century European daily temperature and precipitation series. Int. J. Climatol., 23, 679-692, doi:10.1002/ joc. 906 .

Yamane, Y., T. Hayashi, A. M. Dewan, and F. Akter, 2010: Severe local convective storms in Bangladesh: Part I. Climatology. Atmos. Res., 95, 400-406, doi:10.1016/j.atmosres.2009.11.004.

Yatagai, A., K. Kamiguchi, O. Arakawa, A. Hamada, N. Yasutomi, and A. Kitoh, 2012: APHRODITE: Constructing a long-term daily gridded precipitation dataset for Asia based on a dense network of rain gauges. Bull. Amer. Meteor. Soc., 93, 1401-1415, doi:10.1175/BAMS-D-11-00122.1.

Zhai, P., A. Sun, F. Ren, X. Liu, B. Gao, and Q. Zhang, 1999: Changes of climate extremes in china. Weather and Climate Extremes, T. R. Karl, N. Nicholls, and A. Ghazi, Eds., Springer Netherlands, 203-218.

Zhang, Y., J. M. Wallace, and D. S. Battisti, 1997: ENSO-like interdecadal variability: 1900-1993. J. Climate, 10, 1004-1020.

Manuscript received 15 May 2015, accepted 11 August 2015

SOLA: https://www.jstage.jst.go.jp/browse/sola/ 